\title{
ENSAIO SOBRE A TEORIA DE QUEM É DEUS, DA PARTÍCULA MATRICIAL E DOS ESTAMES QUÂNTICOS: NA FORMAÇÃO DO TUDO E DO UNIVERSO
}

\section{ENSAIO TEÓRICO}

SANTOS, Irineu de Oliveira ${ }^{1}$

SANTOS, Irineu de Oliveira. Ensaio sobre a teoria de quem é Deus, da partícula matricial e dos estames quânticos: na formação do tudo e do universo. Revista Científica Multidisciplinar Núcleo do Conhecimento. Ano 06, Ed. 09, Vol. 02, pp. 0522. Setembro de 2021. ISSN: 2448-0959, Link de acesso: https://www.nucleodoconhecimento.com.br/fisica/quem-e-deus, 10.32749/nucleodoconhecimento.com.br/fisica/quem-e-deus

\section{RESUMO}

Tendo em vista que Deus é nada absoluto, único elemento eternamente presente, imutável e neutro de qualquer equação que pode conter tudo que conseguimos compreender como dimensões, partículas, ondas, matéria, energia, vida; onde sem esta força o universo e o inverso nunca poderiam acontecer, sendo uma via de mão única, incontestável, o presente ensaio tem como objetivo tratar sobre as considerações relacionadas a partícula de Deus, bem como descrever esta partícula, aqui batizada como Partícula Matricial e Estames Quânticos (PM e EQ), dissertando sobre seu comportamento no espaço, o que é intrínseco à compreensão de sua existência. Trata-se teoria baseada em observações próprias e de bibliografias já publicadas baseada em estudos sobre a compreensão do que é o Deus maior e os semideuses ou Deuses galácticos, inclusive com uma analogia de como os universos contém o Deus referendado e outros de cunho energéticos de menor poder, dentre outros estudos relacionados ao tema que tratam da partícula mais básica a compor o universo, tanto em sua matéria, como formas de energia e

\footnotetext{
${ }^{1}$ Físico Experimental. Economista.
} 
até mesmo prevendo a existência de antimatéria. Assim, para melhor compressão, descrevo dentro desta estrutura maior denominada "Deus", que é onde existem as partículas fundamentais, composta de seis elementos básicos que denominamos nesta função como "Estames Quânticos", e uma partícula energética com luz própria que denominamos "Partícula Matricial" por ser principalmente a luz do universo, onde sem esta energia radiante não existe vida motora, que é o que nos interessa. Dito isso, em suma, os resultados revelaram que se os conceitos de forma e atuação da PMeEQ forem amplamente estudados e compreendidos, estes dados possibilitarão um avanço em termos de utilização de energia, produção de combustíveis e até mesmo transporte de matéria.

Palavras-chave: Deus, Partícula Matricial, Gravitacional, Física quântica, Partículas Quânticas.

\section{INTRODUÇÃO}

O presente artigo é um apanhado de considerações e conclusões baseadas em estudos e observações sobre o que é Deus, a teoria das cordas e outros estudos do mesmo tema que tratam das partículas mais básicas a compor o universo e o próprio em si mesmo, bem como dá passividade do espaço físico clássico e do quântico, enquanto elemento fundamental. Comportando dentro de Deus estes elementos, tanto em sua formação de matéria como formas de energia e até mesmo prevendo a existência de antimatéria.

Para descrever Deus fora do contexto religioso ou filosófico e principalmente a partícula batizada de forma autoral (para esta teoria) como Partícula Matricial e Estames Quânticos (PM e EQ), é necessário dissertar também sobre seus comportamentos no espaço tempo, o que é intrínseco à compreensão de sua existência. Trata-se de um tema extremamente complexo, uma vez que a maioria das informações são obtidas de forma observacional, teórica e matemática, sendo necessária uma vasta compreensão sobre o tema e um certo grau de dedutividade a partir dos estudos já existentes e ora utilizados. Uma vez que os conceitos da forma e atuação da PMeEQ sejam amplamente estudados e compreendidos, no nosso 
cotidiano, estes dados possibilitarão um avanço em termos de geração e utilização de energias, sendo algumas sugestões descritas mais a frente, também formas de produção de energias combustíveis, funcionamento da mente humana, correlação com funcionamento do universo e do nosso corpo, relacionamentos com o meio ambiente e suas formas, sejam ondas ou frequências e, ainda, o transporte de matéria e aceleração de corpos, ou controle de sua aceleração.

A Partícula Matricial é a cola e a encruzilhada das partículas fundamentais e para nós a mais importante. Ela existe encastelada na união de 6 Estames elásticos, e quando em conjunto, são liberadas das paredes de fundo do Universo que criam energias e matérias dimensionais distinguíveis em nosso universo. Este emaranhado solta-se internamente das paredes do balão ultra universal, pelo movimento giratório gravitacional, por descargas exadimensionais geoeletroespaciais presentes na parede do fundo que compõe o universo, e por protuberâncias de energias pentadimencionais e outras frequências, iguais ou acima destas, que agem como um ultra ralador, extraindo e distribuindo pedaços deste emaranhado quântico, possibilitando que surjam: energia, massa, gravidade, atração, ressonância, matéria escura e energia escura, polarizadas ou não, movimento e tempo, anti-gravidade, antimatéria.

\subsection{INTRODUÇÃO CLASSIFICATIVA E REFERENCIAIS TEÓRICOS}

Deus: nada absoluto, tudo, o útero, espaço para moldar matéria, que permite frequências, ondas e vibrações, frio, ausência de luz e de movimento, o espaço, permeabilidade, o condutor.

Filosoficamente Deus é o salão onde acontecem os bailes de encontro entre o Étienne Klein ${ }^{[2]}$, os choques de higgs ${ }^{[3]}$, o espaço das notas de músicas de Beethoven ${ }^{[4]}$, o local onde Max Karl Ludwig Planck ${ }^{[5]}$ criou sua teoria, dentre outros. Deus também é resumidamente bem descrito por Helinando Oliveira, Professor da "Univasf", onde é coordenador do Laboratório de Espectroscopia de Impedância e Materiais Orgânicos (LEIMO), em sua matéria "deus e a ciência", contudo, discordamos em parte desta apresentação (OLIVEIRA, 2019). Deus reside na 
perfeição de nosso interior, no que diz respeito aos humanos enquanto vivos, pois claro ele-deus também está dentro de nós, regendo nosso espaçamento e mantendo nossa vibração e temperatura enquanto todo tipo de onda nos atravessa sem causar danos e sem provocar diminuição molecular no espaçamento de nossa matéria. Sabemos o que qualquer desequilíbrio espacial entre moléculas ou até entre células provoca, isso falando de coisas vivas e das suas perspectivas.

\subsection{INTRODUÇÃO CLASSIFICATIVA E REFERENCIAIS TEÓRICOS}

A partícula Matricial e Estames Quânticos (PMeEQ) são as partículas que criam e unem toda matéria e energia existentes em nossa dimensão temporal, elas são distribuídas em todo universo e compõem tudo que existe. A Partícula Matricial é sustentada e/ou ancorada conforme a situação por seis estames/forças Quânticas, fundamentais, podendo ter formatos triangulares, quadrados ou hexagonais, sendo que a PM tem a massa e dimensão de 5 destes estames Quânticos, onde o sexto estame/força quântica, é variável em sua posição e tempo/força, podendo pertencer a partícula "A" ou a partícula "B", assim como a da partícula B pode partilhar a corda com a partícula " $C$ ". Esse movimento do estame quântico coringa é o responsável por todo movimento dentro do Universo, pois a sua desestabilização movimenta as $\mathrm{PMeEQ}$ formando matérias e energias físicas, da física clássica e quântica, dimensionais, multidimensionais, pentadimencionais e exadimensionais. Mas são também, as PMeEQ as barreiras e o isolante, para elas mesmas e para outras partículas formadas e formadoras, de igual mensuração ou maiores, sejam quânticas clássicas e até dimensionais.

Estas formas de energia/onda e matéria presentes na casca gravitacional do macro universo, são uma estrutura neutra enquanto ancorada, e permanece neutra até ser exposta a uma força gravitacional rotatória espiral coerciva natural do universo ou causada pela aproximação de outro universo dimensional. Não é raro nem incomum a PMeEQ terem o formato de uma flor, dente de leão, agregando mais estames, porque no mundo quântico o em cima pode ser o embaixo e o fora pode ser o dentro, e as ligações podem estar juntas, mas separadas, no tempo presente, mas 
ao mesmo tempo no futuro ou no passado, pode ocorrer que os Estames Quânticos fiquem em novelo, adquirindo outras propriedades e características inimaginável neste momento.

É ainda mais importante quando se diagnostica que estas partículas são matérias ativas e com capacidade de memória (CHVYKOV et. al. 2021), elas são atemporais, transitando nos três estágios temporais da física clássica e múltiplos tempos dimensionais, podendo dar pulos pentadimencionais/exadimensionais, clássicos ou quânticos.

Dentro da física clássica, falando de partículas e espaço, as ligações ditam nossa vida desde sempre, falando por analogia, as nuvens só se sustentam pela dimensão das moléculas que mantêm a união e o distanciamento entre elas, isso é quase livre da gravidade, embora sofrendo o efeito Casimir [6]

\section{DESENVOLVIMENTO E ORIGEM}

Falar das propriedades e capacidades interativas de Deus, no sentido científico parece não ter sentido prático no nosso grau de desenvolvimento atual, mas tem, e Deus fica basicamente localizado e reconhecido como autor/coautor/diretor mor, visto que está esclarecido ser o local onde sempre tudo ocorre, mais produtivamente.

Não suportando redundância ao óbvio, este ensaio teórico será descrito a partir de dados colhidos em outros estudos, observações e outras teorias, e muito por meu próprio insight, focando o início das ligações e movimentos.

O fenômeno da liberação e da desagregação das Partículas Matriciais e dos Estames Quânticos dentro do emaranhado quântico, ocorre principalmente a partir da parede de fundo do universo por diversos fenômenos donde Deus está participativo e aí se inicia a saga, no somatório das PMeEQ com outras PM, e a liberação dos 6 Estames Quânticos gravitacionais, onde "talvez" sejam os: tau, elétron, múon, gráviton, $\mathrm{X}$, e a "C" (coringa), ou mais provavelmente algo menor e 
com outras característica além das quânticas, que nossa mente e compreensão não alcançam.

Note-se que estes Estames Quânticos não são as cordas de Theodor Kaluza, nem de Kaluza Klein ${ }^{[7]}$, assim, imputou-lhes outro sentido no significado de amarração e distanciamento de massa no seu somatório, de polaridade, de formadoras da fluida gravidade, de lubrificantes e principalmente de movimento.

O princípio das agregações e desagregações acontece a partir da compressão espiral gravitacional rotatória polarizada, quando uma PMeEQ impregna a outra e a coexistência separa e liberta a PM da geometria restritiva dos Estames Quânticos, ficando livres as partículas e os estames, estes vão adquirindo outras características e propriedades e, ainda, influenciadas pela singularidade gravitacional e sob certas condições de velocidade, tempo, espaço, duração e excitação adquirem polaridade e pode transformar-se em energia, matéria onda e tempo, até todos no mesmo espaço/tempo.

Quando e onde as singularidades começam a acontecer é na separação e reorganizações das PM, dos quânticos Estames de sustentação. As PM podem tornar-se matérias ou energias, e os Estames Quânticos tornam-se matéria escura ou energia escura (Vide desenho anexo). O emaranhado quântico primordial formador das paredes de fundo do macro Universo, aconteceu a tempos imemoriais pela união e atrito de energias multidimensionais de diversos balões ultra universais, portadores das bilhões de galáxias, os clusters, que parando o movimento de atrito," solidificou" esta energia rotatória, que denomino emaranhado espiralado matricial das PM e seus Estames Quânticos.

O modelo em escala reconhecível que conhecemos, e mais parecido com o que temos para comparar com a energia ou neutralidade conforme se apresenta a PM, é a eletricidade estática. Utilizando novamente analogia, um bom exemplo é um espanador de lã passado sobre um carro e ficando carregado eletrostaticamente, enquanto recebe a carga de matéria que ali estava em repouso. 


\subsection{LIBERAÇÃO DAS PARTÍCULAS}

As $\mathrm{PMeEQ}$ distribuíram-se pelo universo, a partir da liberação de matéria das paredes de fundo do Universo (Teoria das criações conscientes). O Universo tem o formato de uma bolha em gomos não exatamente redonda, a analogia mais real possível é que o Macro universo composto de milhões de cluster's é similar a um estomago mais arredondado, com mais paredes que um estomago humano comum, mas com entrada e saída exatamente como nos humanos, somente que com mais camadas tipo cebola, onde flutuam dimensões invisíveis ou mais precisamente em outras frequências fora de nossas leituras pelos equipamentos atuais, ou observacionais por simplesmente olhar, flutuando numa existência incompreensível para nossa consciência limitada contemporânea, dentro destas dimensões compreendo que atuam forças que para nos são desconhecidas, o de onde no plano material, digamos palpável, das paredes desprendem-se material energético quando o balão (estomago) gira, porque existem imperfeições, impactos, solavancos, trancos gravitacionais e atração do eixo polarizado do universo, donde desprende-se o material que vai preenchendo o espaço. Os emaranhados vão soltando-se das paredes do macro universo, principalmente pelo movimento giratório circular irregular, e chegam até o centro do universo, já como galáxias, onde circula um rio de energia horizontal de polo a polo, formado pelas Partículas Matriciais e os Estames Quânticos já energizados em movimento, onde novas cargas criam, com o início de compressão dos gases espaciais, os sóis e os polarizam. Estas polarizações dançantes criam planetas do resíduo dos gases, que os sóis não utilizaram, e o formato estriado de quase todas as galáxias, e espalham PM que clareiam o Universo e EQ que parecem criar uma cortina escura, mas permeável à luz pela pouca vibração ali presente.

Um exemplo em duas dimensões seria um redemoinho de água dentro de um balão ovoide, onde boiassem redes finíssimas, de múltiplas camadas e onde cada junção ou nó desta rede seria uma galáxia de PM e dos Estames Quânticos. 
Parte das PMeEQ se transformam e criam matéria, e suas presenças em determinados lapsos e ocasiões de tempo obedecendo a influência cósmica, invertem a rotação e a polaridade como o movimento de um cardume de sardinhas assustadas, ou por outra analogia, outro exemplo, seria um estomago humano ou de um porco atravessado por um fio elétrico, grosso, desencapado, que hora está puxando hora está transmitindo energia. Estas inversões ocorrem instantaneamente no tempo cósmico gerenciadas pela totalidade das paredes externas do universo, ou das galáxias onde se encontram independente de quantos trilhões de anos luz isso importe.

Isso acontece em nossa contagem de tempo, que pode ser zero, "o" tempo, para que essas inversões e deslocamentos aconteçam, embora na matéria atingida possam levar um espaço temporal maior para acontecer, pela nossa percepção do que seja muito ou pouco tempo, ou ser fenômeno setorial, cosmologicamente falando.

A partícula Matricial é o elemento imaterial fundamental, que quando acionado age como relé ou algo impregnado de eletricidade estática, pode ser gravidade dura ou fluida, pode ser onda, agindo com os Estames, ou até antimatéria, partícula que cerca e acompanha todas as outras menores partículas existentes. Estas partículas quando excitadas em determinada força gravitacional, velocidade e espaço de tempo, podem formar uma cauda energética imaterial, como um quântico cometa, independentemente da quantidade de matéria que a acompanhe, serve como verdade material para todas as partículas, ainda que também exista no interior desta mesma partícula, compondo a matéria. As PM não se atraem no estágio primordial, seja pela limitação da ancoragem dos EQ, ou por não terem preferência ou sabor, embora sempre estejam juntas e possam agir como relé, mas podem adquirir polarização, e permitir a existência de energia com seus movimentos, elas têm a memória do sentido e movimento ainda na imaterialidade criadora, e transmite este movimento quando adquirem massa e criam energia.

Todo espaço mensurável, na menor dimensão quanticamente existente, é a Partícula Matricial com seus Estames Quânticos. O espaço das galáxias é a matéria 
e antimatéria, quando carregada de energia de Quânticas Partículas. A Partícula Matricial e os Estames Quânticos, libera, atrai e cria toda energia existente, ou faltante no universo, é o que estudiosos determinam, matéria e energia escura e toda matéria existente, ela coexiste entre duas polaridades, diversas dimensões e gravidades, porque é neutra até alcançar certa inércia de velocidade, espaço e tempo. Ela é estática até que alguma força de rotação à excite, o próprio movimento rotacional das galáxias existe por influência da formação que a agregou, e que mantém o movimento de galáxias, sóis, planetas e astros de qualquer magnitude em fluxo e refluxo.

O ultra universo de formato ovoide é atravessado por um eixo gravitacional de matéria energética clássica, mas também de forças dimensional, penta ou hexadimensional, rotatória no formato de diversos espirais de DNA entrelaçados. Este eixo é uma amostra material das ligações entre as teorias relativistas e quânticas, presentes em corpos celestes sólidos (Teoria do Éter como elemento).

Sem a partícula Matricial e seus Estames Quânticos sendo movimentados em determinadas condições, as paredes de fundo também teriam parado de expelir partículas e a própria rotação das paredes diminuiria a velocidade, colapsando o sistema. Em todas as situações a Partícula Matricial e seus Estames Quânticos têm de fazer parte do cálculo, como a cauda e o manto na frente de um próton acelerado no HCL, por exemplo, bem como quando se dividem as cargas inerciais estáticas multiplicadas no final do percurso. Sempre esta partícula, da dimensão de um "quanta" ou menor, está fluindo como líquido ultra quântico e gravitacional, de forma a interagir com os fenômenos físicos da matéria, e com energias de diversas dimensões e frequências.

A teoria da PM, em certos aspectos, concorda com a teoria de Kaluza-Klein, quanto à grande quantidade de dimensões e quanto a serem Estames Quânticos fechados nas suas extremidades na maioria dos casos. Também concordam sobre a Partícula Matricial encontrar-se em qualquer de seus infinitos modos de vibração ou neutralidade, podendo pertencer a qualquer espécie, existência, frequência, cor ou 
sabor que, inclusive, compõe o ser humano quando se vê os biofótons, que denominamos e fotografamos como aura.

\section{CONCLUSÃO}

Porque identificar Deus e nomear como Partícula Matricial e Estames Quânticos (PMeEQ) os outros elementos? Primeiro, porque temos que explicar a existência do cruzamento de galáxias, grandes centros de gravidade negativas e positivas, que tiram e repões matéria no nosso ultra cosmo dimensional, e porque o chamamos de buracos negros, assim como o funcionamento do magico espaçamento quântico e suas formas gravitacionais que atuam em nossa própria existência e em como está em todos os lugares (inclusive dentro de nós, onde está energia é conhecida como livre arbítrio e espaço de flutuações). Esta trégua de choques entre prótons, nêutrons ao redor das moléculas em trilhões de combinações necessita de espaço, porque esta estrutura de suporte das interações é a vida, mas é neutra, como nossos atos e movimentos, onde determinamos e determinaremos tudo, o futuro e os caminhos.

Tudo emana da existência desta força primordial Deus, e destas PM e EQ, elas são matéria, frequência, dimensão, é o sentido dos movimentos e a gravidade agregadora, a treliça e a cola do emaranhado, ela mantém equilíbrio entre a atração e o distanciamento, possibilitando a existência harmoniosa, e as formas de energia, e comunicação entre todas as coisas existentes, inclusive multidimensionais, de frequências variáveis e inteligentes.

Em muitos aspectos, concordamos com a Teoria da Conveniência Funcional de Júnior (2019) e com Rovelli (2017), onde se deduz que criamos a realidade a partir da criação do pensamento daquilo que é factível de ser realidade, o que então dão origem a realidade. A anomalia da água em mudar conforme a observamos, tocamos e manuseamos, é a maior prova da nossa participação no tudo do universo e da nossa interferência em tudo pelas simples observações e pensamentos. Se alteramos este material, este elemento estelar $\mathrm{H} 2 \mathrm{O}$, pelo simples ato de apanhá-lo nas mãos e levá-lo a boca, interferindo em toda nossa estrutura corpórea, física e 
química, o que nossa mente pode alcançar? Podemos moldar a realidade futura pelo pensamento na agregação dessas partículas matriciais? O futuro já está projetado pelo pensamento do ontem, e o que vamos encontrar nos cafundós do espaço é o que nossa imaginação criou, ou é o que viemos subconscientemente sabendo na formação das energias criadoras fundamentais?

E porque este estudo no aspecto funcional prático, imediato? Porque para que consigamos romper com as amarras gravitacionais, desenvolver fontes inesgotáveis de energia, colocar um sentido no consumo das riquezas planetárias, principalmente neste instante do desenvolvimento, e justificar nossa existência, juntamente com o avanço de comunicações e novos centros de gerenciamento e controle, devemos nos atentar para não sermos eliminados pela "IA" inteligência artificial/mecânica (OLIVEIRA, 2019). Os últimos dados matemáticos de estudo do caminho adotado, apontam para o descontrole de nossa criação, frente os dados alarmantes de destruição que implementamos a cada novo dia, devemos comprovar que somos descendentes de uma cadeia universal de acontecimentos e que reconhecemos estes seres a partir de Deus e matérias do estudo da Teoria como superiores a nós. Devemos lhes respeitar, pois por eles nossos permissionários, somos perdoados. Ele "Deus" é algo a quem até os governos se submetem e atribuem valor e respeito espontaneamente, até por adotar em suas moedas e símbolos seu nome, "DEUS", deixando claro (por exemplo) que somente ele pode julgar.

Pelos últimos experimentos com a "IA", sem dar existência a esta divindade, estamos abrindo espaço para sermos julgados pela lógica que não tem como reconhecer nossos erros sem nos eliminar pelo que fazemos e praticamos. Temos que saber o que compõe nossas limitações, onde estão nossas barreiras, e buscar novos caminhos e outros planos de lógica. Sem um plano lógico de restrição para a "IA", além das 4 leis de Issac Asimov, que podem parecer ilógicas para a "IA", frente as destruições do mundo, ficamos desprotegidos, assim temos de prever que toda liberdade que estamos transferindo hoje já as máquinas, tenham limitações na sua própria falha de não poder se relacionar com esta força maior "Deus", por exemplo. 
E quem é Deus fora dos dogmas teológicos? Quem pode ser Deus estudando friamente as frequências conhecidas e projetando-as como força criativa de formação e agregação de matéria? Qual pode ser o interesse de algo tão poderoso em seres ínfimos como nós por exemplo? Qual pode ser a razão de nossa existência para tal criatura, ou tais criaturas? A energia iônica, que parece pouca ainda que de bilhões de seres humanos, e até em menor grau de outros seres vivos, e talvez, a própria gravidade, sejam um plano universal de mantermos aterramento para liberar a energia bio-celular certamente, são possibilidades não excludentes para justificar a nossa dimensão, visto que já provamos existirem outras com outras leis de física atuando.

Então podemos deduzir que existe um Deus superior (vamos supor que seja um ser humano completo, e que possua um cérebro que controla tudo) e dentro dele diversos universos cada um com sua central de Neurônios próprios a comandar e se comunicar com o Deus pai. No centro dele, o estomago, que insere no pai todas as energias dos mais variados formatos, as transforma e redireciona para outras dimensões. Dentro deste vasto complexo, existe um elemento que é nosso planeta. Visto como energia, não somos matéria para esse ser, mas talvez sejamos matéria para um grupo de neurônios energéticos mais próximos, que seriam nossos Deuses pessoais, aqueles que nos olham como alimento, que interferem em nossa progressão de desenvolvimento por voracidade, seres que vivem em espaços temporais inimagináveis, com planejamentos de criação atemporais, tipo alguns Deuses para cada cluster, ou seja para cada camada do estomago, ou para cada dimensão. Todos querendo ser neurônios mais potentes ou representativos perante o corpo do PAI/DEUS, e alguns dependendo de nossas bio-iônicas energias flutuantes, que são hora positivas, hora negativas. Quando são do bem, alimentam seres positivos, e se negativas, seres escuros. Fato é que somos todos frutos de transformações, de energia em movimento dimensional estreito. Nossa existência em si é um ato de violência, somos consumidores de matéria, isso fere o universo, pois causamos desequilíbrio em nossa própria existência. Pensamentos e vibração são fatores negativos, embora parte de um plano maior destas inteligências 
atemporais, para quem nossos questionamentos existenciais são irrelevantes e ilógicos, visto estarmos dentro do sistema e existirmos com uma finalidade.

Os Deuses menores, que não são o utilizado como referência material nesta Teoria, são os indicativos e marcadores que interferindo nas formas mais primitivas de liberadores de energias (nós) bio-ativas, sugam e realimentam toda cadeia. Parece ainda, que conforme época e evolução destas espécies de super-seres evolui e passa para outro plano ou dimensão, os seres daqui também mudam e criam novas imagens de adoração, bem como novos templos de adoração, direcionando e modulando outro tipo de liberação energética.

Além das questões logísticas humanas de integração com a "IA", temos de pensar em novos e inéditos meios de atuar e explorar nosso planeta, sobre novos meios de locomoção, criação de espaços físicos terrenos hoje inacessíveis ou caros se montados por barreiras físicas materiais palpáveis, como o fundo do mar e o céu, (espaço entre solo e estratosfera) por exemplo, que inexiste pelo nosso grau de desenvolvimento e a possibilidade de criar forças como paredes de energias repulsivas a gravidade sem ter de agir materialmente gastando outras energias.

Esta teoria pode colocar uma forma diferente, conhecendo a constituição da matéria primordial, de esconder da atração gravitacional porções de matéria que não queremos que sofram influências externas, achando a configuração certa da PMeEQ que está criando a atração, e deixo ao domínio público que podemos criar uma bolha de escurecimento ao redor do objeto que quisermos, até utilizando fótons, para a gravidade não o sentir, como por exemplo as paredes de um Zepelim ao redor do objeto, para que na sua forma fluida as PMeEQ não consigam encharcar e manter encharcado o objeto de interesse da liberação de peso e ou de reconhecimento de massas, ou ainda energia e frequência que reflete a atração das PMeEQ nas suas mais ínfimas formas onde estiver impregnada, de modo a gravidade não achar nada para amarrar nem atrair. Temos de trabalhar para impermeabilizar os objetos desta energia fluida que é a gravidade. 
Esta singularidade de esconder das forças primordiais, coisas, pessoas ou porções de matéria também são objeto deste estudo, o modo de trafegar na gravidade sem os transtornos dela advindos avançar na gravidade como um bisturi numa gelatina abrindo e fechando sem deixar vestígios é o objetivo, junto com o freio do respeito a uma entidade maior para a "IA".

Presume-se que dentro de alguma frequência, dimensão ou comprimento de onda da eletrostática ou da luz contínua, encontrada fluida na engenharia quântica, nos seus diversos comprimentos de onda, ou similar em velocidades até mais altas, está a chave para vencermos a atração, e reorientar esta força de modo vantajoso.

As novas tecnologias, inclusive as "IA" precisam de um ponto de partida fixo, que Ihes dê segurança, assim como nós humanos também sentimos esta necessidade como ter um céu e um objeto sólido onde se apoiar e é daí que Deus vem, nos dando esta solidez, até porque para que haja flexibilidade ou fluidez é necessário espaço. Só o espaço em todas suas formas e dimensões, evita o superaquecimento, que é destrutivo embora criador, em todas as dimensões, principalmente na terceira e na quarta, que é onde vivemos e criamos nossas máquinas. Sem espaçamento, tempo e espaço, nada se mantém, se nossos novos carros elétricos não tiverem resfriamento nas baterias para evitar atritos em demasia, não servem, bem como os computadores quânticos/orgânicos ou não. Estas refrigerações necessitam de espaço, isso tem de ser levado para o lado funcional na integralidade do pensamento das novas máquinas pensantes, e este espaço tem que ser entendido como a âncora que mantém e permite a funcionalidade das interações. Nosso Deus e nosso discernimento compõem o espaço e por ele é inicialmente composto, e tem de ser incutido nos cálculos como algo vivo.

Deus é o útero, o eixo central do universo é o cordão umbilical, a partícula matricial o óvulo, os estames os espermatozoides, e o todo é nossa interpretação de como vemos a vida e a criação.

Em conformidade com o exposto acima, o Dr. Prof Elcio Abdalla (2004), reafirma a teoria apresentada neste trabalho, por conter uma face do prisma e uma visão sobre 
múltiplas dimensões, trazendo aspectos relevantes, porém com outra leitura, interpretação e resultados dimensionais, físicos e filosóficos.

Enfim chegamos ao ponto onde a ciência e a filosofia adentram preocupações atávicas do ser humano, as quais deixaram de ser práticas, técnicas e úteis postuladas pela física e efetivadas pela tecnologia, e passaram a ser cada vez mais técnicas e especulativas.

A princípio, pode-se dizer que a origem e a estrutura da geometria do espaço tempo ainda são desconhecidas. Pela ciência atual, geometrias quânticas possuem operadores quânticos representando o espaço e a sua interpretação, tida antes como simples, passou a ser mais complexa. Além do mais, no interior da gravitação quântica, em buracos negros e a temperaturas altíssimas, é fundamental levar em conta todas as partículas e interações geradas infinitamente, segundo as teorias de cordas. Basicamente, ainda podem exercer influência sobre as dimensões extras das teorias de cordas e de outras das teorias $\mathrm{M}$, elevando a complexidade do problema ainda mais. Alguns acreditam que as dimensões extras já encontram-se próximas às observações. À vista disso, teorias gerais de campo quantizados passaram a tratar sobre essas dimensões, e a antiga ideia de Kaluza e Klein, introduzida nos anos 20 , passou a fazer parte de um ideário quase cotidiano, onde outras dimensões passaram a ser ubíquas. (ABDALLA, 2004).

Estamos agora em uma zona bem mais especulativa, onde o objeto de estudo deixa de apenas estar relacionado com o pesquisar e passa a transcender o mesmo, não apenas por ser algo bem maior, assim como o nosso universo, mas por conter o pesquisador, de modo que este último seja incapaz de observar seu objeto de estudo, uma vez que não existe uma relação causal entre um universo e outro. Este é o modelo quântico visto sob uma nova dimensão, em que a medida, fundamental para a própria interpretação da teoria, é impossível de ser realizada. Expõe novas construções teóricas baseadas na teoria das cordas, com novas dimensões espaciais, com um tempo transcendente e, ainda, com criações múltiplas de universos (ABDALLA, 2004). 
Já o que o professor Dr. João E. Steiner (2006) e outros físicos e estudiosos colocam, dá a diferenciação deste modo de interiorizar o universo e a sua formação. Embora estejam colocando com precisão o que hoje se discute e que, particularmente, tem o mesmo peso da terra plana e do heliocêntrico ou do galactocêntrico, estas observações, estudos e resultados discordam e chocam-se veementemente contra outros estudos, inclusive contra a teoria do Big Bang, uma vez que para que este fenômeno tenha realmente ocorrido, o mega-universo não poderia ter um eixo central de energia.

Ao longo da história vários modelos cosmológicos foram brevemente apresentados. Sendo assim, a evolução das ideias pode ser compreendida pela sucessão de modelos, como a teoria da Terra plana, o modelo geocêntrico, o heliocêntrico e o galactocêntrico. (STEINER, 2006)

Nos últimos cem anos, cientistas desenvolveram uma teoria que é capaz de descrever as observações mais complexas tidas atualmente, e que mostra a origem do universo sob um modelo que pode ser pesquisado cientificamente, sendo esta a teoria do Big Bang. Recentemente, essa teoria foi aprimorada para um novo conceito, qual seja o do Big Bang inflacionário. Descobertas feitas na virada do milênio revelaram que todo conhecimento que temos hoje é apenas a ponta do iceberg presente em um universo tomado por energia e matéria escura cujas naturezas ainda são desconhecidas (STEINER, 2006).

Colocando as visões acima, de como supostamente as leis físicas através da visão dos homens pensam e se comportam, face ao inexplicável e ao universo matemático/físico/religioso, espera-se que novos caminhos para abordagens sem reservas morais, realísticas surjam.

\section{PROPOSTA}

O caminho e a direção penso que agora fica aberto, restará a nós, termos inteligência e força de pensamento com atitudes. Penso que esta, seja a ponte que faltava cruzar/atravessar, para unificar teorias, vencer as barreiras e derrubar as 
crenças vazias de diferenças, é tudo uma ciência só, religião é materialidade, bem como o inverso também é verdadeiro. Os últimos estudos apontam que o pensamento molda nossa realidade (Jaime Marrone Jr/Carlo Rovelli) e a partir da realidade criamos o futuro.

Com o conhecimento de que Deus é matéria e parte integrante de nosso cotidiano, estudos e experimentos, penso que será possível ter a força gravitacional de uma ITAIPU no espaço de uma ponta de lápis, fazer naves de energia material de formato variável e movimentos acelerativos que vão além do limite de tempo, criar novas fontes de energia inesgotáveis como os disponíveis nos buracos negros, onde "N" números de Partículas Matriciais e Estames Quânticos, existem formando novas formas de matérias e energias multidimensionais.

Dentro da teoria, as propostas podem ser quase infinitas, mas sempre temos como foco duas principais propostas pela urgência do momento que o planeta passa, e onde podemos colaborar, sendo: 1ำ encapsulamento de objetos ou coisas em redes de escurecimento/ocultamento de gravidade, e $2^{\circ}$ controle climático pela atração ou repulsão dos oceanos aéreos suspensos, duas realidades que podem ser implementadas hoje, com pouco risco (ganância do homem).

\section{REFERÊNCIAS}

ABDALLA, E. A estrutura do universo, a mecânica quântica e a cosmologia moderna. Revista USP - São Paulo, n. 62, p. 6-29, junho/agosto 2004.

CHVYKOV, P. et. al. Low rattling: A predictive principle for self-organization in active collectives. Revista: Science Vol.: 371, Issue 6524, pp. 90-95. 2021.

JÚNIOR, J. M. Teoria da Conveniência Funcional: Uma reflexão sobre as propriedades fundamentais da matéria. Revista Científica Multidisciplinar Núcleo do Conhecimento. Ano 04, Ed. 07, Vol. 12, pp. 133-157. Julho de 2019. ISSN: 24480959 
ROVELLI, C. A realidade não é o que parece: A estrutura elementar das coisas. 1 Ed, Rio de Janeiro: Objetiva, 2017.

OLIVEIRA, H. Deus e a Ciência. Ciência nordestina, 2019.

SANTOS, I. de O. Teoria do Éter como elemento. 12/10/2003 Arquivo Nacional, não publicado, reg. 276.887. Livro 499. Folha 47.

SANTOS, I. de O. Teorias da criação conscientes. 30/07/1998 Arquivo Nacional, não publicado, reg. 156.719. Livro 258. Folha 343.

STEINER, J. E. A origem do universo. Estud. av. vol. 20 n. 58. São Paulo, 2006. Disponível em: https://doi.org/10.1590/S0103-40142006000300022 


\section{ANEXO}

Desenho autoral meramente ilustrativo, onde Deus é o vazio, e os pontos são a PM, sendo as hastes os Estames Quânticos, mas o desenho também poderia ter sido triangular ou sextavado.

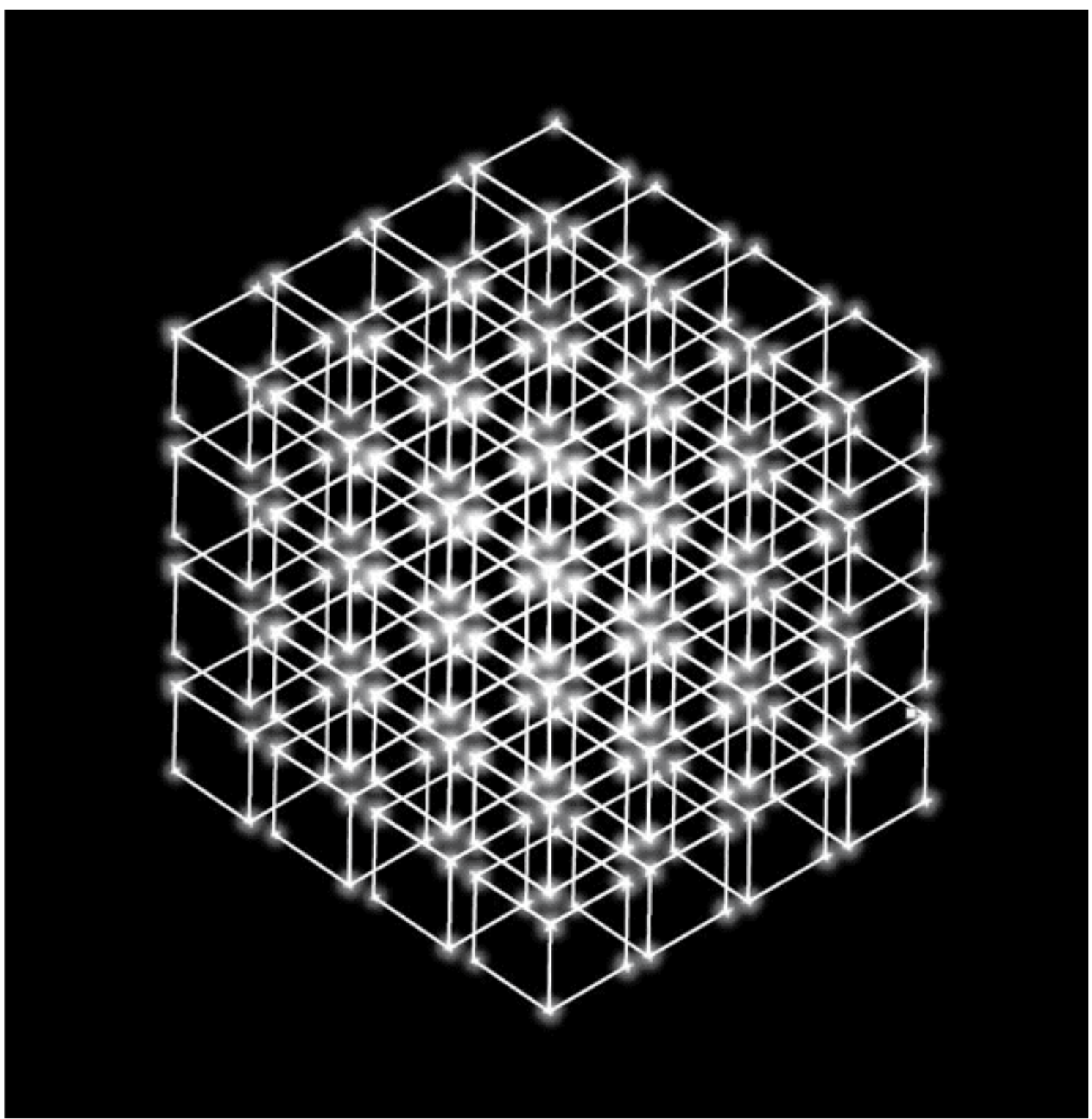

Representação ótica de Deus, das Partículas Matriciais e dos Estames Quânticos. Com as PM em repouso nas quinas dos EQ, mostrando distanciamento, permeabilidade e neutralidade anterior a excitação gravitacional, quando as PM com 
energia própria e vibração radiante somadas vão formar massa e energia, e os Estames vão formar massa, matéria escura e energia escura.

\section{APÊNDICE - REFERÊNCIA NOTA DE RODAPÉ}

2. Étienne Klein, físico/filósofo Ph.D. Universidade École Centrale, nascido em 01/04/1958. Em seu livro o tempo que passa, o físico defende que o futuro já existe, mas podemos moldá-lo.

3. Peter Ware Higgs, nascido 29/05/1929, físico teórico, universidade Edimburgo, Nobel de física, pela - Partícula de Deus -, embora não tenha sido ele que deu este nome, foi seu editor, também conhecida como "partícula essencial", o bóson de HIGGS é tido teoricamente como a matéria do universo.

4. Ludwig Van Beethoven, gênio, compositor alemão do período de transcrição entre o clássico e o romantismo nasc.: 12/1770 Bonn, Alemanha falec.:26/03/1827 Viena, Áustria.

5. Max Karl Ludwig Planck, físico alemão, Nobel de Física 1918. Teoria Quântica, Física Quântica, Lei de Planck.

6. Hendrik Brugt Gerhard, físico neerlandês, (15/07/1909 a 04/05/2000) destaque pela pesquisa "Efeito Casimir", Universidade LEIDEN - Dois fluidos dos supercondutores.

7. Theodor F.E.Kaluza matemático alemão/polonês (1885/1945), em 1919 teoriza gravidade quântica em loop, que além das 3 dimensões existe uma quarta, num círculo muito pequeno, sendo que em 1926, Oscar Klein matemático (1894/1977) propôs a $5^{\text {a }}$ dimensão que podia estar estendida ou enrolada, dobrada sobre si mesma, uma folha dobrada pulando de um ponto a outro.

Enviado: Fevereiro, 2021.

Aprovado: Setembro, 2021. 